\title{
Towards Modernization of the Formulation of the Traditional Uighur Medicine Herbal Preparation Abnormal Savda Munziq
}

\author{
Murat Kizaibek,, ${ }^{1}$ Ruxandra Popescu, ${ }^{2}$ Sonja Prinz, ${ }^{2}$ Halmurat Upur, ${ }^{1}$ \\ Judith Singhuber, ${ }^{2}$ Martin Zehl, ${ }^{2}$ and Brigitte Kopp ${ }^{2}$ \\ ${ }^{1}$ Faculty of Traditional Uighur Medicine, Xinjiang Medical University, Urumqi 830011, China \\ ${ }^{2}$ Department of Pharmacognosy, University of Vienna, Althanstraße 14, 1090 Vienna, Austria \\ Correspondence should be addressed to Brigitte Kopp, brigitte.kopp@univie.ac.at
}

Received 3 January 2011; Revised 6 May 2011; Accepted 20 May 2011

Academic Editor: E. Yesilada

Copyright (C) 2012 Murat Kizaibek et al. This is an open access article distributed under the Creative Commons Attribution License, which permits unrestricted use, distribution, and reproduction in any medium, provided the original work is properly cited.

\begin{abstract}
Abnormal Savda Munziq (ASMq) is a herbal preparation used in Traditional Uighur Medicine for the treatment and prevention of diabetes, cardiovascular diseases, chronic asthma and cancer. The recommended dose of this decoction for cancer patients is $500 \mathrm{~mL}$ administered orally three times a day. Our approach aimed at reducing the high amount of fluid intake required by fractionation of ASMq guided by the antiproliferative activity on HL-60 cells. The fractionation of ASMq resulted in the preparation of an active extract, Extr-4. Using solid phase extraction, Extr-4 was further fractionated into five fractions (SPE-0, SPE-20, SPE-40, SPE-60 and SPE-80), with SPE-40 showing the strongest antiproliferative activity. Caffeic acid, rutin, isoquercitrin, isorhamnetin 3-O-rutinoside, apigenin 7-O-glucoside, rosmarinic acid, luteolin and formononetin were identified in Extr-4 and fractions thereof by means of TLC, HPLC-DAD and LC-MS. SPE-40 contained the main compounds responsible for the antiproliferative activity on HL-60 cells. Thus, a phenolic fraction with high antiproliferative activity on HL-60 cells was obtained from ASMq through the bioassay-guided fractionation process. This could provide a better pharmaceutical formulation that minimizes the administration inconveniencies of a high volume (1.5 L per day) of ASMq decoction for cancer patients.
\end{abstract}

\section{Introduction}

Abnormal Savda Munziq (ASMq) is a medicinal herbal preparation used in the traditional Uighur medicine in Xinjiang region of China [1]. ASMq includes ten medicinal species represented by Cordia dichotoma Forst. f., Anchusa italica Retz., Glycyrrhiza uralensis Fisch., Adiantum capillusveneris L., Euphorbia humifusa Willd., Ziziphus jujuba Mill., Lavandula angustifolia Mill., Foeniculum vulgare Mill., Melissa officinalis L., and Alhagi pseudoalhagi Desv. The mixture is administered as a decoction and is regularly used for the prevention and treatment of diabetes, cardiovascular diseases, chronic asthma, and cancer. For liver, stomach, and colon cancer, the recommended dose of the decoction is $500 \mathrm{~mL}$ three times a day [2].

Recent studies have shown that ASMq can significantly inhibit the growth and viability of Hep G2 human hepatoma cell line [2-4]. ASMq has also been reported to scavenge free radicals [1]. In addition, some species included in ASMq were reported to show in vitro inhibitory activity on different tumor cell lines. For example, G. uralensis inhibited the growth of Hep3B human hepatoma [3] and MCF-7 breast cancer cell line [4]. M. officinalis exerted inhibitory activity against continuous cell culture of HEp- 2 cells derived from human laryngeal cancer [5], HeLa, and MCF-7 cell lines [6]. Z. jujuba decreased the viability of Hep G2 cell line [7]. Some of these species also showed in vitro antiproliferative activities on HL-60 cell line [8].

Although the effect of ASMq and species included in its composition has been recorded on different cancer cells, the high administration volume of the preparation $(1.5 \mathrm{~L}$ per day) is not only inconvenient for the patients, but also adds with a high percentage to the daily recommended fluid intake. The European Food Safety Authority recommends a drinking volume of around $1.5 \mathrm{~L}$ per day. In the USA, The Food and Nutrition Board 2004 states a required amount of fluid intake (water and beverages) of $3 \mathrm{~L}$ per day for adult men and $2.2 \mathrm{~L}$ per day for adult women [9-11]. 
Thus, the consumption of $1.5 \mathrm{~L} \mathrm{day}^{-1}$ of ASMq would represent around $100 \%$ of the required fluid intake as considered by the European forums and around 50\% of the American recommended fluid intake. Therefore, reducing the volume of ASMq decoction, while preserving the antiproliferative effect of the mixture, would provide a more convenient modern formulation for the treatment of cancer patients. The present study aimed at obtaining a highly active antiproliferative fraction of ASMq using bioassay-guided fractionation and cell viability evaluation.

\section{Experimental}

2.1. Plant Materials. Pobumuguo (fruits of C. dichotoma), Niushecao (whole plant of A. italica), Gancao (root of G. uralensis), Tiexianjue (whole plant of A. capillus-veneris), Dijincao (whole plant of E. humifusa), Hongzao (fruits of $Z$. jujuba), Xunyicao (aerial part of L. angustifolia), Xiaohuixiang (fruits of F. vulgare), Mifenghua (whole plant of $M$. officinalis), and Citang (sugar secretion from A. pseudoalhagi) were purchased from Xinjiang Hospital of Traditional Uighur Medicine, Urumqi, China in September 2007. The plant material used was unprocessed.

2.2. Chemicals and Reagents. Luteolin, rosmarinic acid, apigenin 7-O-glucoside and isorhamnetin 3-O-rutinoside were obtained from Extrasynthèse (Genay, France), caffeic acid from Sigma-Aldrich (St. Louis, Mo, USA), and formononetin, rutin, isoquercitrin and gallic acid from Carl Roth (Karlsruhe, Germany). Acetonitrile (HPLC grade) was purchased from VWR International (Leuven, Belgium). Glacial acetic acid (purity > 99.8\%) and DMSO were obtained from Carl Roth (Karlsruhe, Germany). FolinCiocalteu's phenol reagent was purchased from Merck (Darmstadt, Germany), HPD-300 macroporous resin from Cang Zhou Bonchem Co., Ltd. (Hebei, China), Polyamide resin from Taizhou Luqiao Biochemical Corporation (Zhejiang, China), SPE Mega Bond Elut C-18 cartridges from Varian (Middelburg, The Netherlands). TLC silica gel $60 \mathrm{~F}_{254}$ plates were obtained from Merck (Darmstadt, Germany). All other reagents used were of analytical grade.

\subsection{Preparation and Fractionation}

2.3.1. Preparation of ASMq. ASMq was prepared according to a previously reported procedure [12]. The plant material was separately ground and mixed in the following ratio: C. dichotoma (10.6), A. italica (10.6), G. uralensis (7.1), A. capillus-veneris (4.9), E. humifusa (4.9), Z. jujuba (4.9), L. angustifolia (4.9), F. vulgare (4.9), M. officinalis (4.9), and A. pseudoalhagi (42.3). The mixture was decocted in boiling water in a ratio of $1: 10(\mathrm{w} / \mathrm{v})$ for $3 \mathrm{~h}$. After filtration, the residue was reextracted for $3 \mathrm{~h}$, two times in the same volume of boiling water. The resulting crude extract was filtered, evaporated to dryness under reduced pressure, and pulverized. The obtained powder was used for this study. The yield was $39.9 \%(\mathrm{w} / \mathrm{w})$ with respect to the total mass of dry materials.
2.3.2. Preparation of Different Extracts of ASMq. $350 \mathrm{~g}$ dry extract of ASMq was dissolved in $1050 \mathrm{~mL}$ hot $\mathrm{H}_{2} \mathrm{O}\left(60^{\circ} \mathrm{C}\right)$, filtered, and cooled to room temperature. The resulting solution was passed through a column $(125 \mathrm{~cm} \times 5 \mathrm{~cm})$ filled with HPD-300 macroporous adsorbent resin. The column was eluted with 3 bed volumes (BV) of $\mathrm{H}_{2} \mathrm{O}$ dest. The $\mathrm{H}_{2} \mathrm{O}$ eluate was concentrated, and then $95 \% \mathrm{EtOH}$ was added to obtain a final concentration of $70 \% \mathrm{EtOH}$. The mixture was stirred for $10 \mathrm{~min}$. The resulting precipitate was collected and redissolved in $\mathrm{H}_{2} \mathrm{O}$ and the $\mathrm{EtOH}$ precipitation was repeated once again. The resulting precipitate was decolored with activated carbon and evaporated under reduced pressure to obtain extract 1 (Extr-1, 54.9 g). The HPD-300 macroporous column was sequentially eluted with $3 \mathrm{BV}$ of $20 \% \mathrm{EtOH}$ and $3 \mathrm{BV}$ of $60 \% \mathrm{EtOH}$, and the resulting eluates were collected separately and evaporated under reduced pressure to dryness to obtain extract 2 (Extr-2, $15.7 \mathrm{~g}$ ) and extract 3 (Extr-3, $25.3 \mathrm{~g})$, respectively. The yields (w/w) of Extr-1, Extr-2, and Extr-3 were $15.69 \%, 4.49 \%$, and $7.23 \%$ of the dry weight of ASMq, respectively.

2.3.3. Preparation of Extract 4. Dry extract of ASMq ( $350 \mathrm{~g}$ ) was dissolved in $1050 \mathrm{~mL}$ hot $\mathrm{H}_{2} \mathrm{O}\left(60^{\circ} \mathrm{C}\right)$ and filtered. 1.5 volumes of $95 \% \mathrm{EtOH}$ were added; the mixture was stirred for $20 \mathrm{~min}$ and then allowed to stand for $24 \mathrm{~h}$. The resulting supernatant layer was filtered, concentrated under reduced pressure to $350 \mathrm{~mL}$ and subjected to column chromatography $(125 \mathrm{~cm} \times 5 \mathrm{~cm})$ on polyamide resin. The column was eluted first with $\mathrm{H}_{2} \mathrm{O}$ dest. (3 BV), followed by $60 \% \mathrm{EtOH}(3 \mathrm{BV})$. The fraction eluted with $\mathrm{H}_{2} \mathrm{O}$ dest. was discarded, while the fraction eluted with $60 \% \mathrm{EtOH}$ was evaporated under reduced pressure to dryness to obtain extract 4 (Extr-4, 12.2 g). The yield (w/w) of Extr-4 was $3.49 \%$ with respect to the dry weight of ASMq.

2.3.4. Fractionation of Extr-4. Extr-4 was further fractionated by solid phase extraction (SPE). $50 \mathrm{mg}$ of Extr-4 were dissolved in $1 \mathrm{~mL} \mathrm{MeOH} 40 \%$ and applied onto an SPE column preconditioned with 2 reservoir volumes (RV) $\mathrm{MeOH}$ and $2 \mathrm{RV} \mathrm{H}_{2} \mathrm{O}$. The cartridge was sequentially eluted with $2 \mathrm{RV}$ of $\mathrm{H}_{2} \mathrm{O}$ and $20 \%, 40 \%, 60 \%$, and $80 \% \mathrm{MeOH}$ at a

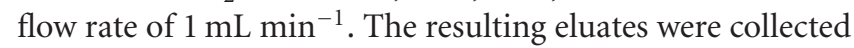
separately and evaporated under reduced pressure to yield SPE-0 (1.1 mg), SPE-20 (1.0 mg), SPE-40 (11.7 mg), SPE$60(11.9 \mathrm{mg})$ and SPE-80 (5.2 $\mathrm{mg})$, respectively. The yields $(\mathrm{w} / \mathrm{w})$ of these fractions were $0.15 \%$ (SPE-0), 0.14\% (SPE20), 1.63\% (SPE-40), 1.66\% (SPE-60), and 0.73\% (SPE-80) of the dry weight of ASMq, respectively.

A flow chart of the ASMq preparation and fractionation procedure is shown in Figure 1.

2.4. Cell Culture. The HL-60 human promyelocytic leukemia cell line was obtained from the American Type Culture Collection (ATCC). Cell medium RPMI 1640 and its supplements were obtained from Life Technologies, Inc., USA. The HL-60 cells were routinely cultured in RPMI 1640 medium, supplemented with $10 \%(\mathrm{v} / \mathrm{v})$ heat inactivated foetal bovine 


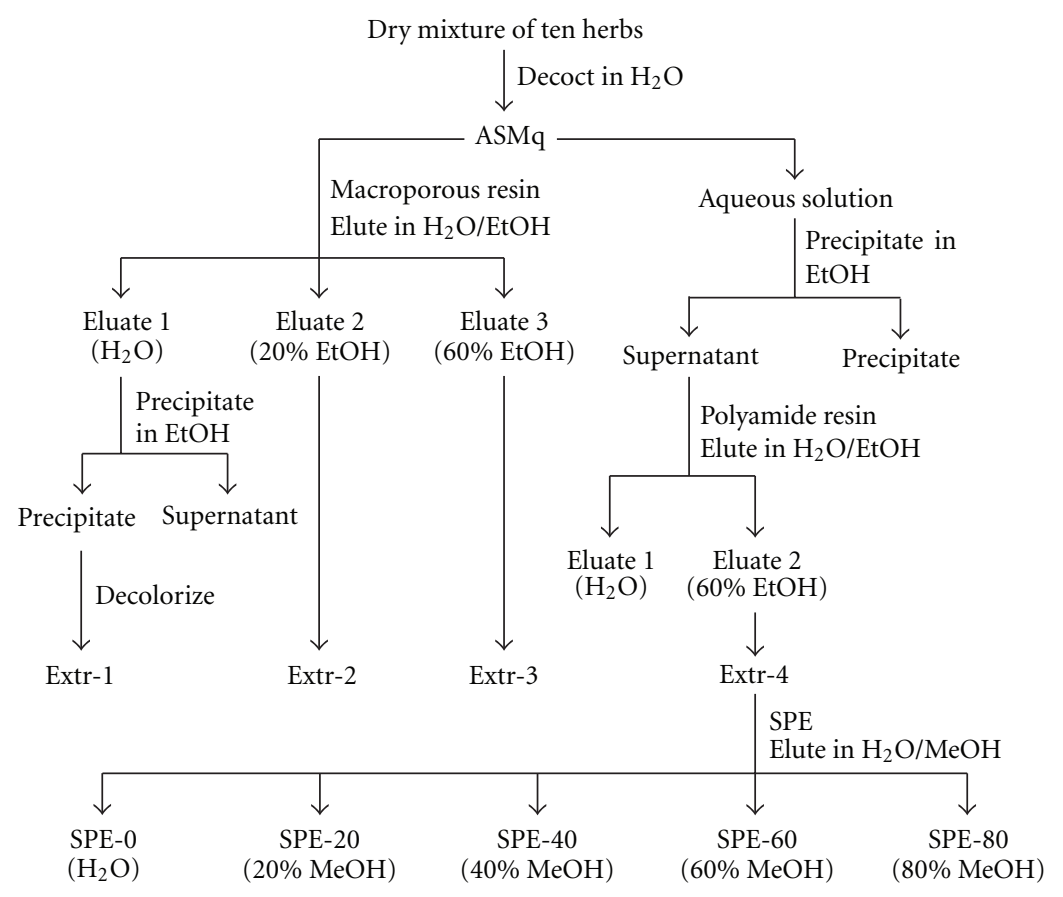

FIGURE 1: A flow chart of the ASMq preparation and fractionation procedure.

serum, 1\% L-glutamine, and 1\% penicillin/streptomycin and grown in a humidified atmosphere with $5 \% \mathrm{CO}_{2}$ at $37^{\circ} \mathrm{C}$.

2.5. Evaluation of Cell Viability. Cells were seeded at a density of $0.1 \times 10^{6}$ cells $\mathrm{mL}^{-1}$ in 12 -well plates and grown for $24 \mathrm{~h}$. Cells were then incubated with $100 \mu \mathrm{g} \mathrm{mL}^{-1}$ and $250 \mu \mathrm{g} \mathrm{mL}^{-1}$ ASMq, extracts (Extr-1, Extr-2, Extr-3, and Extr-4) and $50 \mu \mathrm{g} \mathrm{mL}^{-1}$ SPE fractions (SPE-0, SPE-20, SPE40, SPE-60, and SPE-80), respectively. In order to determine the $\mathrm{IC}_{50}$ value of Extr-4, cells were exposed to increasing concentrations $\left(0,25,50,100,200\right.$, and $\left.250 \mu \mathrm{g} \mathrm{mL}^{-1}\right)$ of Extr4. Prior to use, the stock solutions of all dry extracts (ASMq extracts and SPE fractions) were prepared in 60\% EtOH and then filtered through $0.20 \mu \mathrm{m}$ sterile syringe filters. The final concentration of $\mathrm{EtOH}$ in culture medium during the treatment of cells did not exceed $0.5 \%(\mathrm{v} / \mathrm{v})$. Vehicle-treated cells $(0.5 \% \mathrm{EtOH})$ were tested as control samples. After $24 \mathrm{~h}$, $48 \mathrm{~h}$, and $72 \mathrm{~h}$ of incubation, the cells were stained with tryptan blue $(0.4 \%)$ and counted with a cell counter (ViCELL XR Cell Viability Analyzer, Beckman, USA). The cell viability was expressed as the percentage of control. Analyses were performed in triplicate, values are given as mean \pm SD.

2.6. TLC Analysis. TLC analyses of ASMq extracts and SPE fractions were performed on silica gel $60 \mathrm{~F}_{254}$ plates. Extr-1, Extr-2, Extr-3, and Extr-4 were dissolved in $\mathrm{H}_{2} \mathrm{O}, 20 \% \mathrm{EtOH}$, $40 \% \mathrm{EtOH}$, and $60 \% \mathrm{EtOH}$, respectively $\left(20 \mathrm{mg} \mathrm{mL}^{-1}\right)$, and $10 \mu \mathrm{L}$ aliquots were applied to a TLC plate. As mobile phase $\mathrm{CHCl}_{3} / \mathrm{MeOH} / \mathrm{H}_{2} \mathrm{O}(70: 22: 3.5, \mathrm{v} / \mathrm{v} / \mathrm{v})$ was used, the plate was sprayed with $0.5 \%$ fast blue salt B aqueous solution [13]. Evaluation was done under visible light. Rosmarinic acid was used as reference compound.
SPE fractions were dissolved in $60 \% \mathrm{MeOH}(20 \mathrm{mg}$ $\mathrm{mL}^{-1}$ ) and $5 \mu \mathrm{L}$ aliquots were applied to a TLC plate and developed with EtOAc/HCOOH/HAc/ $\mathrm{H}_{2} \mathrm{O}$ (100: $11: 11: 26$, $\mathrm{v} / \mathrm{v} / \mathrm{v} / \mathrm{v})$. The plate was then sprayed with natural products spraying reagent ( $1 \%$ methanolic diphenylboric acid- $\beta$ ethylamino ester) followed by $5 \%$ ethanolic polyethylene glycol-4000 [13]. The plate was investigated under $365 \mathrm{~nm}$. Rutin, hyperoside, and astragalin were used as reference compounds.

2.7. HPLC-DAD and LC-MS Analysis. HPLC-DAD analyse was conducted on a Shimadzu LC-10AD liquid chromatograph equipped with a SCL-10A system operator, a SPDM20A diode array detector, a SIL-10AD auto injector and a DGU-14A degasser. The LC-MS analyses were performed on an UltiMate 3000 RSLC-series system (Dionex, Germering, Germany) coupled to a 3D quadrupole ion trap mass spectrometer equipped with an orthogonal ESI source (HCT, Bruker Daltonics, Bremen, Germany). HPLC separation was carried out on a Hypersil BDS-C18 column $(4 \times 250 \mathrm{~mm}$, $5 \mu \mathrm{m}$, Thermo Scientific, Waltham, Mass, USA) at a flow rate of $1.2 \mathrm{~mL} \mathrm{~min}^{-1}$. Water ( $\mathrm{pH} 2.8$ with acetic acid) and MeCN (with the same amount of acetic acid) were used as mobile phase $\mathrm{A}$ and $\mathrm{B}$, respectively. The following gradient program was used: 15\% B (0 min), 41.3\% B (45 min), 95\% B (46 min), and $95 \% \mathrm{~B}(51 \mathrm{~min})$. The eluent flow was split roughly $1: 8$ before the ESI ion source, which was operated as follows: capillary voltage: $3.7 \mathrm{kV}$, nebulizer: $30 \mathrm{psi}\left(\mathrm{N}_{2}\right)$, dry gas flow: $8 \mathrm{~L} \mathrm{~min}^{-1}\left(\mathrm{~N}_{2}\right)$, and dry temperature: $340^{\circ} \mathrm{C}$. The mass spectrometer was operated in an automated data-dependent acquisition (DDA) mode where each MS scan $(\mathrm{m} / z$ 801100 , average of 5 spectra) was followed by $\mathrm{MS}^{2}$ scans $(\mathrm{m} / z$ 40-1100, average of 3 spectra, isolation window of $4 \mathrm{Th}$, 
fragmentation amplitude of $1.0 \mathrm{~V}$ ) of the two most intense precursor ions, and $\mathrm{MS}^{3}$ scans $(\mathrm{m} / \mathrm{z} 40-1100$, average of 3 spectra, isolation window of $4 \mathrm{Th}$, fragmentation amplitude of $1.0 \mathrm{~V}$ ) of the most intense fragment ion in each $\mathrm{MS}^{2}$ scan. In additional LC-MS experiments, the instrument was operated in alternating ion $\mathrm{MS}^{1}$ mode.

The sample injection volume was $10 \mu \mathrm{L}$. 2 mg of Extr- 4 as well as $2 \mathrm{mg}$ of each of the SPE fractions were separately sonicated with $1 \mathrm{~mL}$ of $60 \% \mathrm{MeOH}-\mathrm{DMSO}(4: 1, \mathrm{v} / \mathrm{v})$ for $5 \mathrm{~min}$ at room temperature. Standard phenolic compounds were dissolved in $\mathrm{MeOH}$. Identification of compounds was achieved by comparing retention times as well as UV and $\mathrm{MS}^{n}$ spectra.

2.8. Total Flavonoid Content. The total flavonoid content was determined by aluminium nitrate method [14]. $30 \mathrm{mg}$ of ASMq and $3 \mathrm{mg}$ of Extr-4 were dissolved in $1 \mathrm{~mL} \mathrm{H}_{2} \mathrm{O}$ and $1 \mathrm{~mL}$ of $60 \% \mathrm{EtOH}$ in a $5 \mathrm{~mL}$ volumetric flask, respectively. $2 \mathrm{~mL}$ of $\mathrm{H}_{2} \mathrm{O}$ and $0.15 \mathrm{~mL}$ of aqueous $5 \% \mathrm{NaNO}_{2}$ solution were added, followed by $0.15 \mathrm{~mL}$ of $10 \% \mathrm{Al}\left(\mathrm{NO}_{3}\right)_{3} 6 \mathrm{~min}$ later. The mixture was allowed to stand for another $6 \mathrm{~min}$ at room temperature. Then, $1 \mathrm{~mL}$ of $1 \mathrm{M} \mathrm{NaOH}$ was added. The sample was immediately diluted with $\mathrm{H}_{2} \mathrm{O}$ to a final volume of $5 \mathrm{~mL}$ and mixed. A blank without sample solution was prepared in parallel. Rutin was used as standard to establish the calibration curve. Absorbances of samples were determined at $510 \mathrm{~nm}$ on a spectrophotometer (Beckman DU-640). Total flavonoid content was expressed as mg rutin equivalent (RUE) $\mathrm{g}^{-1}$ dried extract. Data for ASMq and Extr- 4 were reported as mean \pm SD for five replicates and for triplicates, respectively.

2.9. Total Phenolic Content. The Folin-Ciocalteu method was used to determine the total phenolic content [15]. $160 \mu \mathrm{L}$ of sample $\left(6 \mathrm{mg}\right.$ ASMq dissolved in $1 \mathrm{~mL} \mathrm{H}_{2} \mathrm{O}$ and $0.6 \mathrm{mg}$ Extr-4 dissolved in $1 \mathrm{~mL} 60 \% \mathrm{EtOH}$, respectively) were added to a $5 \mathrm{~mL}$ volumetric flask and diluted with $\mathrm{H}_{2} \mathrm{O}$ dest. to $2.5 \mathrm{~mL}$. $0.25 \mathrm{~mL}$ of Folin-Ciocalteu reagent were added. 6 min later, $0.75 \mathrm{~mL}$ of $20 \%$ aqueous $\mathrm{Na}_{2} \mathrm{CO}_{3}$ solution were added, diluted with $\mathrm{H}_{2} \mathrm{O}$ to a final volume of $5 \mathrm{~mL}$ and mixed. After incubation at room temperature for $2 \mathrm{~h}$, the absorbance of the reaction mixture was measured at $765 \mathrm{~nm}$ against a blank containing only solvent and reagents. Gallic acid was used as standard for the calibration curve. Total phenolic content was expressed as mg gallic acid equivalent (GAE) $\mathrm{g}^{-1}$ dried extract. Data for ASMq and Extr-4 were reported as a mean \pm SD for five replicates and for triplicates, respectively.

2.10. Statistical Analysis. The results of cell viability were presented as means \pm SD. Statistical comparison was performed using the one-way analysis of variance (ANOVA) followed by Tukey's test (in case of equal variance) or Dunnett's T3 test (in case of unequal variance). These tests were performed using SPSS 13 for Windows. $P<0.05$ was considered statistically significant. IC $_{50}$ values and their $95 \%$ confidence limits were estimated by a sigmoidal dose-response model with variable slope (GraphPad Prism software, version 4.03).

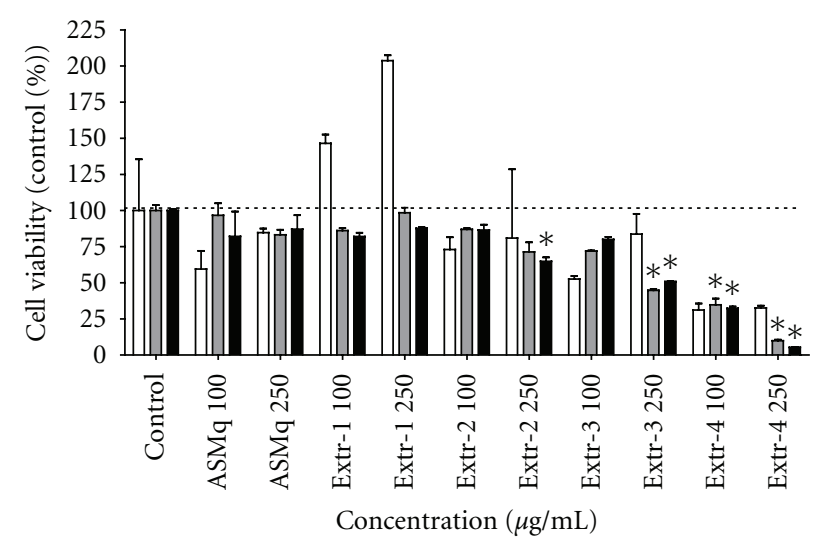

$\square 24 \mathrm{~h}$
$\square \quad 48 \mathrm{~h}$
$\square 72 \mathrm{~h}$

Figure 2: Effect of ASMq, Extr-1, Extr-2, Extr-3, and Extr-4 on the viability of HL-60 cells. Cells were seeded in 12-well plates, grown for $24 \mathrm{~h}$ and then treated with $100 \mu \mathrm{g} / \mathrm{mL}$ and $250 \mu \mathrm{g} / \mathrm{mL} \mathrm{ASMq}$, Extr-1, Extr-2, Extr-3, and Extr-4. After $24 \mathrm{~h}, 48 \mathrm{~h}$, and $72 \mathrm{~h}$ cell viability was assessed by tryptan blue exclusion method. Data represent the percentage of control value and are expressed as mean \pm SD of triplicate cultures. ${ }^{*} P<0.05$, as compared to control cells.

\section{Results and Discussion}

In the first step of this study, three extracts, Extr-1, Extr2, and Extr-3, were obtained from ASMq by macroporous resin chromatography and tested for their effect on cell viability. Figure 2 shows the activity of ASMq and the corresponding extracts on HL-60 cell viability. ASMq and Extr-1 $\left(250 \mu \mathrm{g} \mathrm{mL}^{-1}\right)$ showed no remarkable cytotoxicity after $72 \mathrm{~h}$, reducing cell viability to $87.1 \pm 16.7 \%$ and $87.7 \pm$ $1.3 \%$, respectively. Extr-1 enhanced cell proliferation after $24 \mathrm{~h}$ for both tested concentrations (100 and $250 \mu \mathrm{g} \mathrm{mL}^{-1}$ ). ASMq was previously reported to contain 58\% saccharides as glucose equivalents [16]. Therefore, the enhanced cell proliferation of HL-60 cells after $24 \mathrm{~h}$ in the presence of Extr1 could be due to the high content of saccharides in these extracts. Unlike ASMq and Extr-1, Extr-2 $\left(250 \mu \mathrm{g} \mathrm{mL}^{-1}\right)$ showed higher cytotoxicity, inducing a decline in cell viability to $64.8 \pm 4.8 \%$, while Ext-3 $\left(250 \mu \mathrm{g} \mathrm{mL}^{-1}\right)$ exhibited the highest cytotoxicity, decreasing cell viability to $50.83 \pm$ $0.70 \%$ after $72 \mathrm{~h}$. Thus, ASMq showed no remarkable activity on HL-60 cell proliferation at the given concentration, while different effects on cell viability were distributed between the three extracts obtained from ASMq, with the most apolar of the extracts showing increased antiproliferative effect. The low activity of ASMq is in line with the high dose of ASMq decoction (1.5 L per day) required for the treatment of cancer patients. The result of TLC analysis revealed that phenolic compounds were absent in Extr-1 but could be detected in Ext-2 and Extr-3. When compared to Extr-2, Extr-3 showed an enriched phenolic fingerprint. This implied a possible correlation between the phenolic compounds and the cytotoxic activity on HL-60 cells. Therefore, a polyamide chromatography was performed on ASMq to obtain an extract enriched in phenolic compounds. The resulting 
extract, Extr-4, showed higher cytotoxicity than Extr-2 and Extr-3, reducing cell viability to $5.29 \pm 0.28 \%$ at a concentration of $250 \mu \mathrm{g} \mathrm{mL} L^{-1}$, after $72 \mathrm{~h}$ (Figure 2). Figure 3 shows the dose-response curve for Extr- 4 when tested on HL-60 cells after $24 \mathrm{~h}, 48 \mathrm{~h}$, and $72 \mathrm{~h}$. The IC 50 values were $105.7 \mu \mathrm{g} \mathrm{mL}^{-1}$ (24 h), $95.1 \mu \mathrm{g} \mathrm{mL}^{-1}(48 \mathrm{~h})$ and $72.3 \mu \mathrm{g} \mathrm{mL} \mathrm{L}^{-1}(72 \mathrm{~h})$.

According to preliminary TLC analysis, the number of phenolic compounds increased from Extr-1 to Extr-4 with the majority present in the latter. The total flavonoid content and total phenolic content of ASMq were $25 \pm$ $1 \mathrm{mgRUE} \mathrm{g}^{-1}$ dried extract and $38 \pm 1 \mathrm{mg} \mathrm{GAE} \mathrm{g}^{-1}$ dried extract, respectively, whereas those of Extr-4 were $221 \pm$ $9 \mathrm{mg} \mathrm{RUE} \mathrm{g}^{-1}$ dried extract and $333 \pm 7 \mathrm{mg} \mathrm{GAE} \mathrm{g}^{-1}$ dried extract, respectively. Both the flavonoid content and the phenolic content increased to approximately 9-fold in Extr-4 versus ASMq. These results confirmed that the phenolic compounds were enriched in Extr-4 through polyamide resin chromatography.

Using SPE, Extr-4 was further fractionated into five fractions, SPE-0, SPE-20, SPE-40, SPE-60, and SPE-80. According to cell viability assessment after $72 \mathrm{~h}$, all fractions showed various degrees of cytotoxicity on HL-60 cells (Figure 4). SPE-40 $\left(50 \mu \mathrm{g} \mathrm{mL}{ }^{-1}\right)$ was found to exhibit the strongest inhibitory effect on the viability of HL-60 cells by inducing a time-dependent decrease in cell viability to $8.2 \pm$ $1.5 \%$. The TLC analyses revealed the presence of flavonoids in all SPE fractions except SPE-80. The majority of flavonoids were present in SPE-40, implying that flavonoids may be the most active phenolic compounds in SPE-40.

The identification of phenolic compounds in Extr-4 and SPE fractions was performed using HPLC-DAD and LCMS. The HPLC chromatogram of Extr-4 recorded at $254 \mathrm{~nm}$ is shown in Figure 5. Eight phenolic compounds, namely, caffeic acid (1), rutin (2), isoquercitrin (3), isorhamnetin 3-O-rutinoside (4), apigenin 7-O-glucoside (5), rosmarinic acid (6), luteolin (7), and formononetin (8), were identified in Extr-4 by comparison of their retention time, and UV and MS spectral characteristics to those of standards in Figure 5(a), as well as by spiking the sample with standards. The chemical structures of compounds $\mathbf{1} \sim \mathbf{8}$ are shown in Figure 6. Several phenolic compounds that have been described as chemical constituents of the species included in ASMq, such as chlorogenic acid, luteolin 3',7-O-diglucoside, ferulic acid, eriodictyol 7-O-glucoside, narirutin, rhamnetin, rhoifolin, and isovitexin, were not found in Extr-4. Some of the phenolic compounds we identified in Extr-4 by LC-MS were also found in SPE-0, SPE-20, SPE-40, and SPE-60. For example, 1, 2, and 6 were identified in SPE-0 (Figure 7(a)) and SPE-20 (Figure 7(b)) in varying ratios. Five phenolic compounds, 2-6, were identified in SPE-40 (Figure 7(c)), whereas 4, 7, and 8 were found in SPE-60 (Figure 7(d)). Compound 3 was identified only in SPE-40. Based on the results of TLC and HPLC analyses, SPE-80 may not contain phenolic compounds (Figure 7(e)) but is mainly enriched in licorice triterpene saponins (e.g., glycyrrhizic acid) according to tentative identification by LC-MS (data not shown).

Phenolic compounds are well studied secondary plant metabolites that have been thoroughly investigated due to their presence in the human diet and their biological

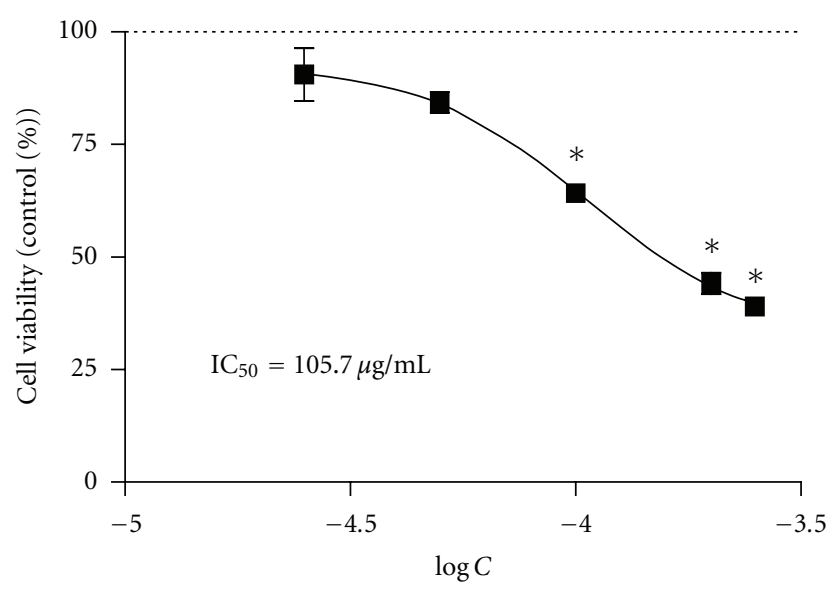

(a)

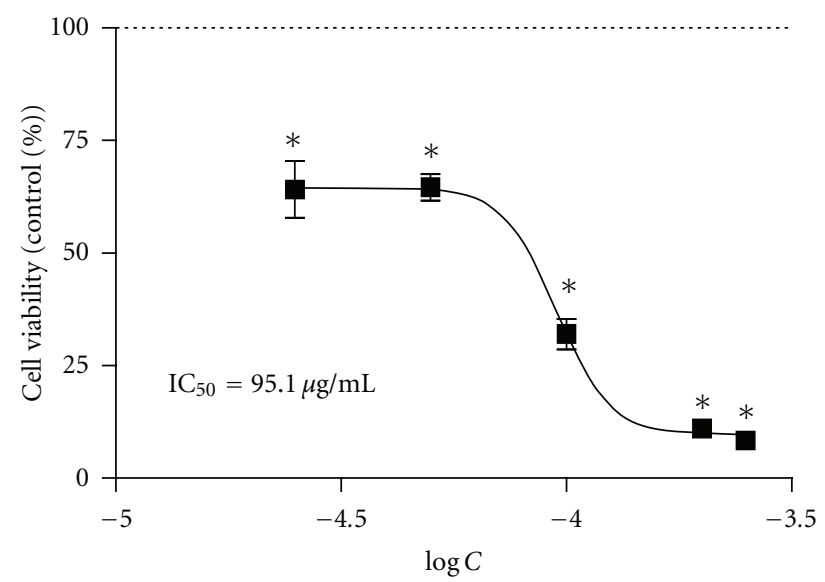

(b)

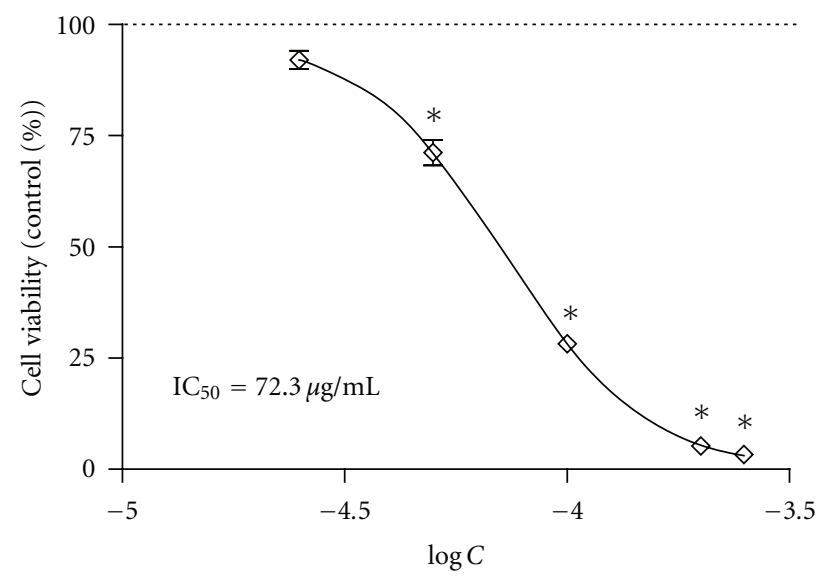

(c)

FIgure 3: Dose-response curves of antiproliferative activity of Extr-4 after $24 \mathrm{~h}$ (a), $48 \mathrm{~h}$ (b), and $72 \mathrm{~h}$ (c). HL-60 cells were cultured in 12-well plates for $24 \mathrm{~h}$ to reach logarithmic growth phase and then incubated with $25-250 \mu \mathrm{g} / \mathrm{mL}$ Extr-4. Cell viability was estimated by tryptan blue staining and cell counting after $24 \mathrm{~h}, 48 \mathrm{~h}$, and $72 \mathrm{~h}$. Data are presented as percentage of control value. The horizontal axis represents a log scale of concentration of Extr-4. The $\mathrm{IC}_{50}$ was calculated using a sigmoidal dose-response model with variable slope. The curve represents the average of experiments performed in triplicate. ${ }^{*} P<0.05$, compared with respective control value $(24 \mathrm{~h}: 100.00 \pm 8.50 \%$; $48 \mathrm{~h}: 100.00 \pm$ $8.84 \%, 72 \mathrm{~h}: 100.00 \pm 22.26 \%$ ). 


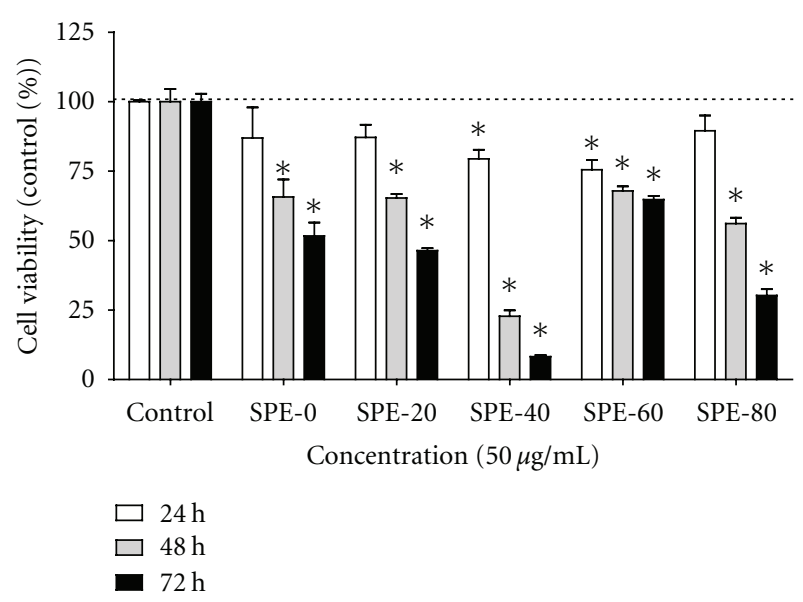

Figure 4: Viability of HL-60 cells after $24 \mathrm{~h}, 48 \mathrm{~h}$, and $72 \mathrm{~h}$ of treatment with SPE-0, SPE-20, SPE-40, SPE-60, and SPE-80 subfractions. Cell viability was assessed by tryptan blue exclusion method and is presented as percentage of control value. Data are expressed as mean \pm SD of two independent experiments, each of which was done in triplicate. ${ }^{*} P<0.05$, compared with control. Each sample was tested at a concentration of $50 \mu \mathrm{g} / \mathrm{mL}$.

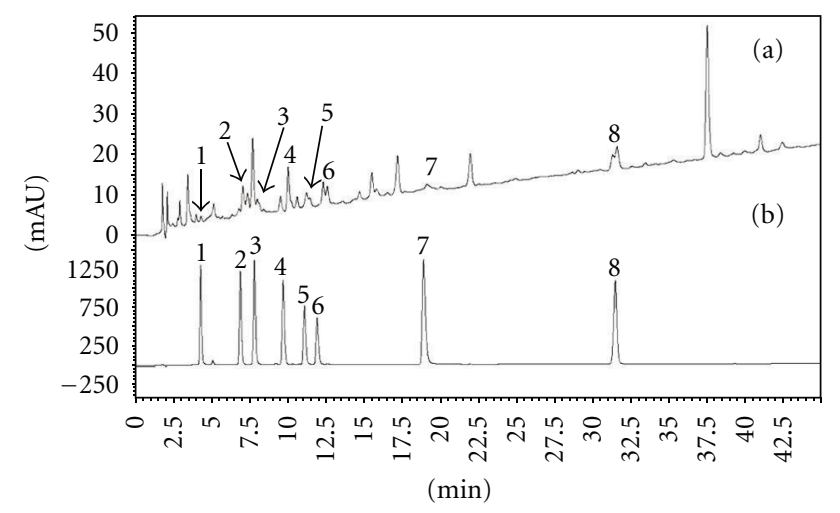

FIGURE 5: Reversed phase HPLC chromatograms of standard phenolic compounds (a) and Extr-4 (b) at a wavelength of $254 \mathrm{~nm}$. (1) caffeic acid, (2) rutin, (3) isoquercitrin, (4) isorhamnetin 3O-rutinoside, (5) apigenin 7-O-glucoside, (6) rosmarinic acid, (7) luteolin, and (8) formononetin.

properties, including their beneficial effects on health. One of these effects is their capacity to interfere with all stages of the cancer process $[17,18]$. Several flavonoids have been shown to suppress carcinogenesis in various animal models [19]. A growing number of epidemiological studies suggest that high flavonoid intake may be correlated with decreased cancer risk [20-22].

The phenolic compounds detected in Extr-4 and its SPE fractions were also previously identified in species from the composition of ASMq. For example, 1 was identified in $L$. angustifolia [23] and M. officinalis [24], 2 in Z. jujuba [25], A. capillus-veneris [26], C. dichotoma [27], G. uralensis [28], and F. vulgare [29], and 3 in A. capillus-veneris [26], G. uralensis [28], and M. officinalis [30]. 4 was found in $C$. dichotoma [27], G. uralensis [28], and F. vulgare [29] and 5 in E. humifusa [31] and M. officinalis [30]. 6 was identified in C. dichotoma [27], F. vulgare [29], and M. officinalis [24]. 7 and 8 were found in M. officinalis [32] and G. uralensis [33], respectively.

Compounds 2 [34] and 8 [35] were reported to possess no remarkable cytotoxicity on HL-60 cells. 4 showed no distinctive cytotoxicity on HT-29 human colon carcinoma, MCF-7 human breast carcinoma, and Hep G2 human hepatoma cell lines [36]. 3 showed antiproliferative effects on B16F10 murine melanoma [37] and MCF-7 human breast carcinoma cell lines [38]. $\mathbf{5}$ possessed moderate cytotoxic effects on human prostate cancer cell lines derived from different metastatic sites, such as LNCaP, DU145, and PC3 cells [39]. 1 [40] and 6 [41] showed low cytotoxic effects on HL-60 cell line, while 7 [42] exhibited a strong cytotoxic activity on HL-60 cells. Thus, the phenolic compounds identified in Extr-4 have been previously shown to have no remarkable $(2,4,8)$, moderate $(1,3,5,6)$, or strong $(7)$ cytotoxic effect on different cancer cell lines.

SPE- 0 and SPE-20 contain compounds that have been described as moderate cytotoxic which can explain their observed activity in the viability tests. The concentration of 7 , a strong cytotoxic compound, in SPE-60 was low as shown by the HPLC analysis, justifying the moderate effect of this fraction. The characterization of SPE-40, the most active fraction, identified compounds described as moderate $(3,5,6)$ or very low cytotoxic $(2,4)$, suggesting that 3,5 , and 6 could, at least in part, contribute to the antiproliferative activity of SPE-40 on HL-60 cells. The mechanisms of antiproliferative effects of these compounds were investigated in some studies. For example, $\mathbf{3}$ was reported to reduce glioblastoma cell growth without inducing apoptosis, possibly by modulating the control of the cell cycle. It was also suggested that $\beta$-catenin-mediated signaling may be involved on the antiproliferative activity of 3 [43]. 5 inhibited cancer cell growth through deconjugation of glycosides that occurs in the cellular compartment to produce aglycone and apigenin [44]. Apigenin itself exhibits a significant growth inhibition against hepatoma cell lines and induces apoptosis in Hep G2 cells [45]. Its apoptotic mechanism might be mediated through the p53-dependent pathway and the induction of p21 expression [45] or through a mitochondria/caspase-pathway [46]. It was also reported that apigenin inhibits cancer cell proliferation through G2/M cell cycle arrest [47] and $\operatorname{Er} \beta$ [48]. The authors have found no report on the mechanism underlining the antiproliferative activity of $\mathbf{6}$ against cancer cells.

However, these results also imply that the identified phenolics are not the only compounds responsible for the antiproliferative activity of SPE-40 and suggest the possible presence of one or more compounds with stronger activity. The latter could contribute to the cytotoxicity of the identified phenolic compounds by both additive and synergistic effects. The majority of the uncharacterized compounds in SPE-40 showed UV-Vis spectral characteristics similar to flavanones, chalcones, and ellagic acid derivatives (data not shown), which were reported to possess strong antiproliferative activities on different cancer cells [49-52]. This could also be confirmed by LC-MS, which indicates the 
<smiles>O=C(O)/C=C/c1ccc(O)c(O)c1</smiles>

1<smiles>[R20]Oc1cc(O)c2c(=O)c([R1])c(-c3ccc(O)c([R3])c3)oc2c1</smiles>

$2 \mathrm{R}_{1}=-\mathrm{O}$-Rutinose, $\mathrm{R}_{2}=\mathrm{H}, \mathrm{R}_{3}=\mathrm{OH}$

$3 \mathrm{R}_{1}=-\mathrm{O}-\mathrm{Glc}, \mathrm{R}_{2}=\mathrm{H}, \mathrm{R}_{3}=\mathrm{OH}$

$4 \quad \mathrm{R}_{1}=-\mathrm{O}-$ Rutinose, $\mathrm{R}_{2}=\mathrm{H}, \mathrm{R}_{3}=\mathrm{OCH}_{3}$

$5 \quad \mathrm{R}_{1}=\mathrm{H}, \mathrm{R}_{2}=-\mathrm{O}-\mathrm{Glc}, \mathrm{R}_{3}=\mathrm{H}$<smiles>O=C(/C=C/c1ccc(O)c(O)c1)OC(Cc1ccc(O)c(O)c1)C(=O)O</smiles><smiles>O=c1cc(-c2ccc(O)c(O)c2)oc2cc(O)cc(O)c12</smiles>

7<smiles>COc1ccc(-c2coc3cc(O)ccc3c2=O)cc1</smiles>

8

Figure 6: Compounds identified in Extr-4 and its fractions: (1) caffeic acid, (2) rutin, (3) isoquercitrin, (4) isorhamnetin 3-O-rutinoside, (5) apigenin 7-O-glucoside, (6) rosmarinic acid, (7) luteolin, and (8) formononetin.

presence of several typical liquorice flavanones (e.g., liquiritin apioside, liquiritin, and liquiritigenin) and chalcones (e.g., isoliquiritin apioside and isoliquiritin) based on the comparison of multistage MS data with published results (data not shown) [53], indicating that phenolic compounds, with possible strong antiproliferative activity, constitute most of the remaining uncharacterized compounds in SPE-40.

\section{Conclusion}

In summary, our study focused on the bioassay-guided fractionation of ASMq aiming at the reduction of the administration volume of the ASMq decoction $\left(1.5 \mathrm{~L} \mathrm{day}^{-1}\right)$ and the modernization of its pharmaceutical formulation.
Four extracts, namely, Extr-1, Extr-2, Extr-3, and Extr-4, were prepared from ASMq. Extr-4 exerted the strongest antiprolifertive activity on HL-60 cells. Extr- 4 was further fractionated into five fractions by solid phase extraction, of which SPE-40 showed the strongest inhibitory effect on HL60 cells. The results of the cell viability assay, quantification assay, and the TLC and LC-MS analyses on Extr-4 and the SPE fractions revealed that the main bioactive components with antiproliferative activity against HL-60 cell line could be phenolic compounds. The substances identified in Extr-4 and its SPE fractions were caffeic acid, rutin, isoquercitrin, isorhamnetin 3-O-rutinoside, apigenin 7-O-glucoside, rosmarinic acid, luteolin, and formononetin. Isoquercitrin, apigenin 7-O-glucoside, and rosmarinic acid may contribute 


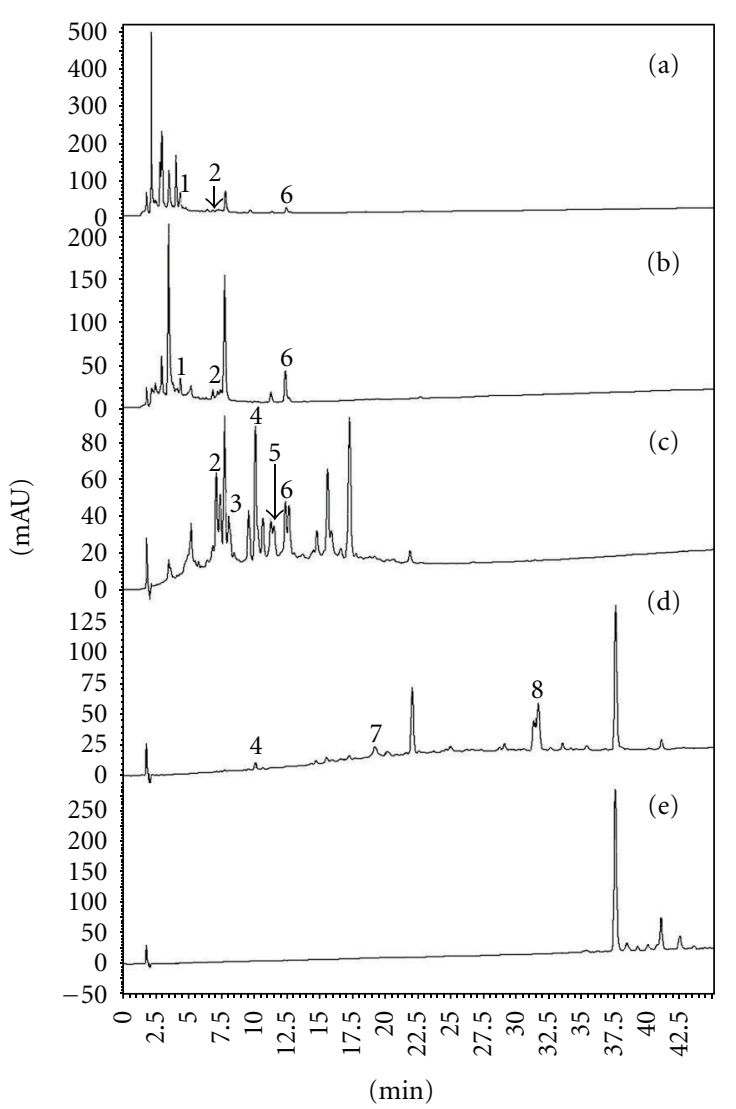

Figure 7: HPLC chromatograms of five SPE fractions at a wavelength of $254 \mathrm{~nm}$. (a) SPE-0, (b) SPE-20, (c) SPE-40, (d) SPE60, (e) SPE-80, (1) caffeic acid, (2) rutin, (3) isoquercitrin, (4) isorhamnetin 3-O-rutinoside, (5) apigenin 7-O-glucoside, (6) rosmarinic acid, (7) luteolin, and (8) formononetin.

to the cytotoxicity of SPE- 40 on HL-60 cells. The results also suggest that other compounds than the identified phenolics add to the antiproliferative effect of ASMq. However, fraction SPE-40 obtained in the course of our work could significantly reduce the high therapeutic dosage of ASMq $(500 \mathrm{~mL}$ three times a day). One dose of ASMq was reduced from $500 \mathrm{~mL}$ ( $200 \mathrm{~g}$ dry weight) to $1.6 \mathrm{~g}$ fraction SPE-40. Thus, the bioassay-guided fractionation of ASMq could lead to the enrichment of active compounds in an active fraction and to the diminution of the administration dose of the TCM preparation, providing a better pharmaceutical formulation for cancer patients.

\section{Acknowledgments}

The first author is thankful to Eurasia Pacific Uninet for providing the scholarship. This research work is part of the project "Quality Assurance of Herbal Medicinal Products (HMPs) from TCM", aided by the Austrian Federal Ministry of Science and Research and the Federal Ministry for Health, Family, and Youth and was also funded by the Cultivation Fund of the Key Scientific and Technical Innovation Project Ministry of Education, China (no. 708058). The authors wish to present their acknowledgements also to Katharina Tschernow for her contribution to the fractionation of Extr-4.

\section{References}

[1] A. Yusup, H. Upur, A. Umar, and N. Moore, "Protective effects of Munziq and Mushil of abnormal Savda to mitochondrial oxidative damage," Fundamental \& Clinical Pharmacology, vol. 18, no. 4, pp. 471-476, 2004.

[2] H. Upur, A. Yusup, I. Baudrimont et al., "Inhibition of cell growth and cellular protein, DNA and RNA synthesis in human hepatoma (HepG2) cells by ethanol extract of abnormal Savda Munziq of traditional Uighur medicine," Evidence-Based Complementary and Alternative Medicine, vol. 2011, Article ID 251424, 9 pages, 2011.

[3] W. T. Chung, S. H. Lee, and J. D. Kim, "Effect of the extracts from Glycyrrhiza uralensis Fisch on the growth characteristics of human cell lines: anti-tumor and immune activation activities," Cytotechnology, vol. 37, no. 1, pp. 55-64, 2001.

[4] E. H. Jo, H. D. Hong, and N. C. Ahn, "Modulations of the Bcl2/Bax family were involved in the chemopreventive effects of licorice root (Glycyrrhiza uralensis Fisch) in MCF-7 human breast cancer cell," Journal of Agricultural \& Food Chemistry, vol. 52, no. 6, pp. 1715-1719, 2004.

[5] A. Allahverdiyev, N. Duran, S. Cetiner, and M. Ozguven, "Investigation of the anticancerogenic effect of the essential oil of Melissa officinalis L," Pharmaceutical \& Pharmacological Letters, vol. 11, no. 1, pp. 26-29, 2001.

[6] J. Canadanović-Brunet, G. Cetković, S. Djilas et al., "Radical scavenging, antibacterial, and antiproliferative activities of Melissa officinalis L. extracts," Journal of Medicinal Food, vol. 11, no. 1, pp. 133-143, 2008.

[7] X. Huang, A. Kojima-Yuasa, T. Norikura, D. O. Kennedy, T. Hasuma, and I. Matsui-Yuasa, "Mechanism of the anti-cancer activity of Zizyphus jujuba in HepG2 cells," American Journal of Chinese Medicine, vol. 35, no. 3, pp. 517-532, 2007.

[8] M. Kizaibek, B. Kopp, S. Prinz, S. Popescu, and H. Upur, "Antiproliferative activity of individual herbs of abnormal savda Munziq on HL-60 cells," Keji Daobao, vol. 27, pp. 9498, 2009.

[9] M. J. Bossingham, N. S. Carnell, and W. W. Campbell, "Water balance, hydration status, and fat-free mass hydration in younger and older adults," American Journal of Clinical Nutrition, vol. 81, no. 6, pp. 1342-1350, 2005.

[10] EFSA, "Draft dietary reference values for water," Scientific Opinion of the Panel on Dietetic Products, Nutrition and Allergies, 2008.

[11] E. Jéquier and F. Constant, "Water as an essential nutrient: the physiological basis of hydration," European Journal of Clinical Nutrition, vol. 64, no. 2, pp. 115-123, 2010.

[12] A. Yusup, H. Upur, I. Baudrimont et al., "Cytotoxicity of abnormal savda Munziq aqueous extract in human hepatoma (HepG2) cells," Fundamental \& Clinical Pharmacology, vol. 19, no. 4, pp. 465-472, 2005.

[13] H. Wagner and S. Bladt, Plant Drug Analysis: A Thin Layer Chromatography Atlas, Springer, 1996.

[14] Committee CP, Pharmacopoeia of the P. R. China, Chemical Industry Press, Beijing, China, 2005.

[15] Y. Y. Soong and P. J. Barlow, "Antioxidant activity and phenolic content of selected fruit seeds," Food Chemistry, vol. 88, no. 3, pp. 411-417, 2004. 
[16] M. Kizaibek, H. Upur, and K. Amut, "Determination of total saccharides and total saponins in abnormal savda Munziq," Keji Daobao, vol. 27, pp. 39-42, 2009.

[17] G. G. Duthie, S. J. Duthie, and J. A. M. Kyle, "Plant polyphenols in cancer and heart disease: implications as nutritional antioxidants," Nutrition Research Reviews, vol. 13, no. 1, pp. 79-106, 2000.

[18] P. C. H. Hollman, "Evidence for health benefits of plant phenols: local or systemic effects?" Journal of the Science of Food \& Agriculture, vol. 81, no. 9, pp. 842-852, 2001.

[19] J. D. Lambert, J. Hong, G. Y. Yang, J. Liao, and C. S. Yang, "Inhibition of carcinogenesis by polyphenols: evidence from laboratory investigations," The American Journal of Clinical Nutrition, vol. 81, no. 1, pp. 284S-291S, 2005.

[20] R. Garcia-Closas, C. A. Gonzalez, A. Agudo, and E. Riboli, "Intake of specific carotenoids and flavonoids and the risk of gastric cancer in Spain," Cancer Causes \& Control, vol. 10, no. 1, pp. 71-75, 1999.

[21] P. Knekt, J. Kumpulainen, R. Jarvinen et al., "Flavonoid intake and risk of chronic diseases," American Journal of Clinical Nutrition, vol. 76, no. 3, pp. 560-568, 2002.

[22] L. Le Marchand, S. P. Murphy, J. H. Hankin, L. R. Wilkens, and L. N. Kolonel, "Intake of flavonoids and lung cancer," Journal of the National Cancer Institute, vol. 92, no. 2, pp. 154-160, 2000.

[23] C. Proestos, N. Chorianopoulos, G. J. E. Nychas, and M. Komaitis, "RP-HPLC analysis of the phenolic compounds of plant extracts. Investigation of their antioxidant capacity and antimicrobial activity," Journal of Agricultural \& Food Chemistry, vol. 53, no. 4, pp. 1190-1195, 2005.

[24] B. Klimek, T. Majda, J. Gora, and J. Patora, "Investigation of essential oil and phenolic compounds of lemon balm (Melissa officinalis L.) cultivated in Poland," Herba Polonica, vol. 44, pp. 324-331, 1998.

[25] C. Souleles and G. Shammas, "Flavonoids from the leaves of Zizyphus jujuba," Fitoterapia, vol. 59, p. 154, 1988.

[26] F. Imperato, "New phenolic glycosides in the fern adiantum capullis-veneris L," Chemistry \& Industry, pp. 957-958, 1982.

[27] Y. Wang, K. Ohtani, R. Kasai, and K. Yamasaki, "Flavonol glycosides and phenolics from leaves of Cordia dichotoma," Natural Medicines, vol. 50, no. 5, p. 367, 1996.

[28] S. S. Jia, C. M. Ma, Y. H. Li, and J. H. Hao, "Glycosides of phenolic acid and flavonoids from the leaves of Glycyrrhiza uralensis Ficsh," Yao Xue Xue Bao, vol. 27, no. 6, pp. 441-444, 1992.

[29] I. Parejo, O. Jauregui, F. Sánchez-Rabaneda, F. Viladomat, J. Bastida, and C. Codina, "Separation and characterization of phenolic compounds in fennel (Foeniculum vulgare) using liquid chromatography-negative electrospray ionization tandem mass spectrometry," Journal of Agricultural \& Food Chemistry, vol. 52, no. 12, pp. 3679-3687, 2004.

[30] A. Mulkens and I. Kapetanidis, "Flavonoids from leaves of Melissa officinalis L. (Lamiaceae)," Pharmaceutica Acta Helvetiae, vol. 62, no. 1, pp. 19-22, 1987.

[31] W. Z. Liu, H. Wang, and L. Kong, "Studies on chemical constituents of Euphorbia humifusa," Zhong Cao Yao, vol. 32, pp. 107-108, 2001.

[32] T. Mencherini, P. Picerno, C. Scesa, and R. Aquino, "Triterpene, antioxidant, and antimicrobial compounds from $\mathrm{Me}$ lissa officinalis," Journal of Natural Products, vol. 70, no. 12, pp. 1889-1894, 2007.
[33] H. Bai, D. Dou, Y. Pei, Y. Chen, and L. Wu, "Isolation and structure identification of chemical constituents in cultivated Glycyrrhiza uralensis," Zhong Cao Yao, vol. 36, pp. 652-654, 2005.

[34] S. C. Shen, Y. C. Chen, F. L. Hsu, and W. R. Lee, "Differential apoptosis-inducing effect of quercetin and its glycosides in human promyeloleukemic HL-60 cells by alternative activation of the caspase 3 cascade," Journal of Cellular Biochemistry, vol. 89, no. 5, pp. 1044-1055, 2003.

[35] T. H. Kang, S. J. Jeong, W. G. Ko et al., "Cytotoxic lavandulyl flavanones from Sophora flavescens," Journal of Natural Products, vol. 63, no. 5, pp. 680-681, 2000.

[36] M. L. Xu, G. Li, D. C. Moon et al., "Cytotoxicity and DNA topoisomerase inhibitory activity of constituents isolated from the fruits of Evodia officinalis," Archives of Pharmacal Research, vol. 29, no. 7, pp. 541-547, 2006.

[37] L. O. Regasini, A. A. Lopes, D. H. S. Silva et al., "Antiproliferative effect of Pterogyne nitens on melanoma cells," Revista de Ciencias Farmaceuticas Basica Aplicada, vol. 28, no. 3, pp. 335-340, 2007.

[38] J. C. Le Bail, F. Varnat, J. C. Nicolas, and G. Habrioux, "Estrogenic and antiproliferative activities on MCF-7 human breast cancer cells by flavonoids," Cancer Letters, vol. 130, no. 1-2, pp. 209-216, 1998.

[39] J. K. Srivastava and S. Gupta, "Antiproliferative and apoptotic effects of chamomile extract in various human cancer cells," Journal of Agricultural \& Food Chemistry, vol. 55, no. 23, pp. 9470-9478, 2007.

[40] E. Sergediene, K. Jönsson, H. Szymusiak, B. Tyrakowska, I. M. C. M. Rietjens, and N. Cenas, "Prooxidant toxicity of polyphenolic antioxidants to HL-60 cells: description of quantitative structure-activity relationships," FEBS Letters, vol. 462, no. 3, pp. 392-396, 1999.

[41] A. Nitzsche, S. V. Tokalov, H. O. Gutzeit, and J. Ludwig-Müller, "Chemical and biological characterizition of cinnamic acid derivatives from cell cultures of lavender (Lavandula officinalis) induced by stress and jasmonic acid," Journal of Agricultural \& Food Chemistry, vol. 52, no. 10, pp. 2915-2923, 2004.

[42] W. G. Ko, T. H. Kang, S. J. Lee, Y. C. Kim, and B. H. Lee, "Effects of luteolin on the inhibition of proliferation and induction of apoptosis in human myeloid leukaemia cells," Phytotherapy Research, vol. 16, no. 3, pp. 295-298, 2002.

[43] N. G. Amado, D. M. Cerqueira, F. S. Menezes, J. F. Mendes da Silva, V. M. Neto, and J. G. Abreu, "Isoquercitrin isolated from hyptis fasciculata reduces glioblastoma cell proliferation and changes $\beta$-catenin cellular localization," Anti-Cancer Drugs, vol. 20, no. 7, pp. 543-552, 2009.

[44] J. K. Srivastava and S. Gupta, "Extraction, characterization, stability and biological activity of flavonoids isolated from chamomile flowers," Molecular \& Cellular Pharmacology, vol. 1, no. 3, pp. 138-147, 2009.

[45] L. C. Chiang, L. T. Ng, I. C. Lin, P. L. Kuo, and C. C. Lin, "Antiproliferative effect of apigenin and its apoptotic induction in human Hep G2 cells," Cancer Letters, vol. 237, no. 2, pp. 207-214, 2006.

[46] E. J. Choi and G. H. Kim, "Apigenin induces apoptosis through a mitochondria/caspase-pathway in human breast cancer MDA-MB-453 cells," Journal of Clinical Biochemistry and Nutrition, vol. 44, no. 3, pp. 260-265, 2009.

[47] M. B. Ujiki, X. Z. Ding, M. R. Salabat et al., "Apigenin inhibits pancreatic cancer cell proliferation through G2/M cell cycle arrest," Molecular Cancer, vol. 5, article 76, 2006. 
[48] P. Mak, Y. K. Leung, W. Y. Tang, C. Harwood, and S. M. Ho, "Apigenin suppresses cancer cell growth through ER $\beta$," Neoplasia, vol. 8, no. 11, pp. 896-904, 2006.

[49] C. Pouget, F. Lauthier, A. Simon et al., "Flavonoids: structural requirements for antiproliferative activity on breast cancer cells," Bioorganic \& Medicinal Chemistry Letters, vol. 11, no. 24, pp. 3095-3097, 2001.

[50] T. Takahashi, M. Kobori, H. Shinmoto, and T. Tsushida, "Structure-activity relationships of flavonoids and the induction of granulocyticor monocytic-differentiation in HL60 human myeloid leukemia cells," Bioscience, Biotechnology \& Biochemistry, vol. 62, no. 11, pp. 2199-2204, 1998.

[51] J. N. Losso, R. R. Bansode, A. Trappey, H. A. Bawadi, and R. Truax, "In vitro anti-proliferative activities of ellagic acid," Journal of Nutritional Biochemistry, vol. 15, no. 11, pp. 672-678, 2004.

[52] M. Cabrera, M. Simoens, G. Falchi et al., "Synthetic chalcones, flavanones, and flavones as antitumoral agents: biological evaluation and structure-activity relationships," Bioorganic \& Medicinal Chemistry, vol. 15, no. 10, pp. 3356-3367, 2007.

[53] G. Tan, Z. Zhu, H. Zhang et al., "Analysis of phenolic and triterpenoid compounds in licorice and rat plasma by high-performance liquid chromatography diode-array detection, time-of-flight mass spectrometry and quadrupole ion trap mass spectrometry," Rapid Communications in Mass Spectrometry, vol. 24, no. 2, pp. 209-218, 2010. 


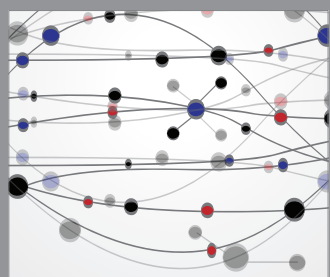

The Scientific World Journal
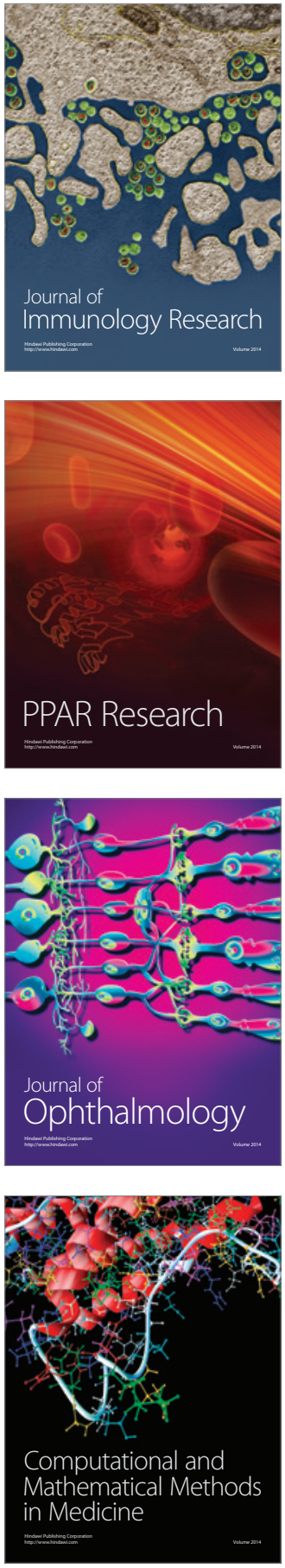

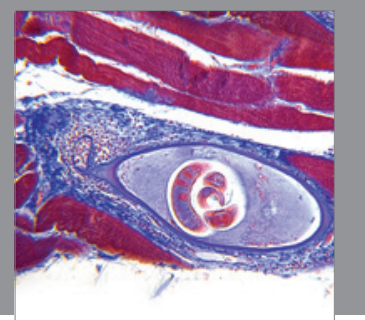

Gastroenterology

Research and Practice
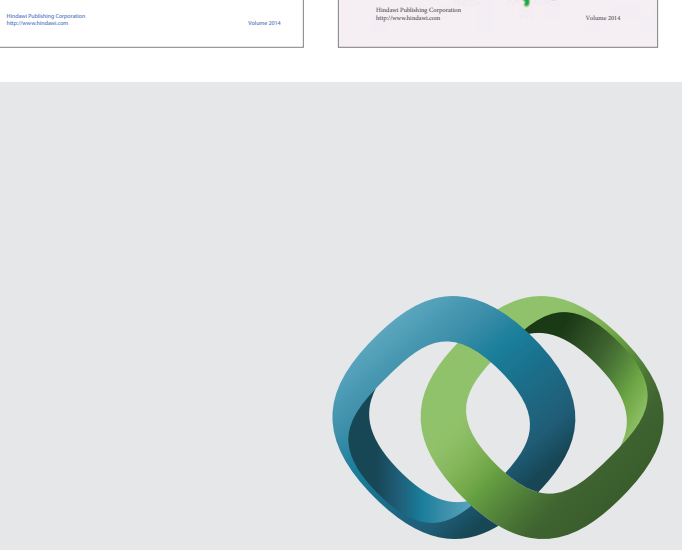

\section{Hindawi}

Submit your manuscripts at

http://www.hindawi.com
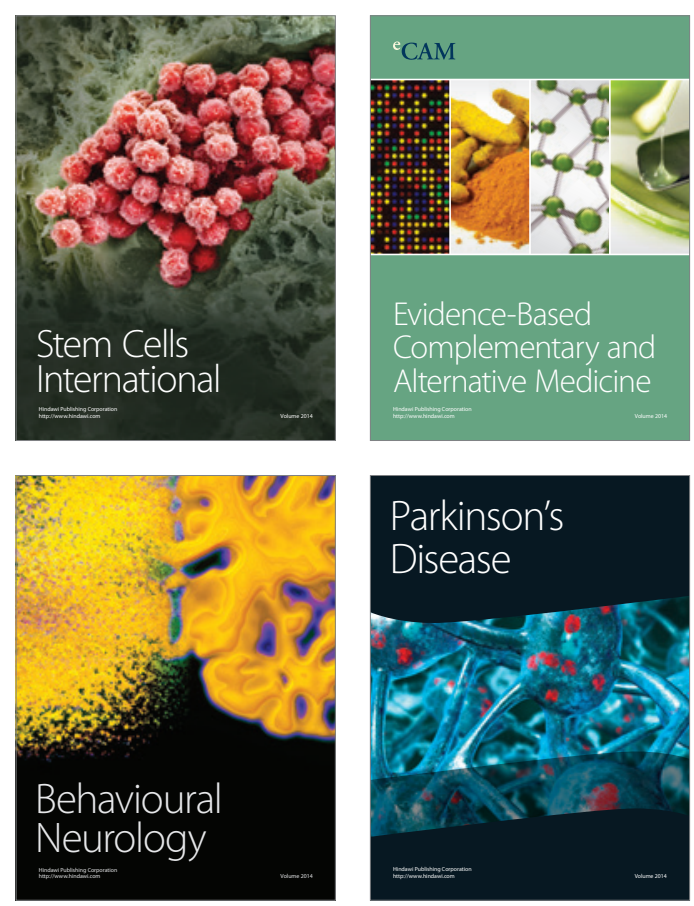

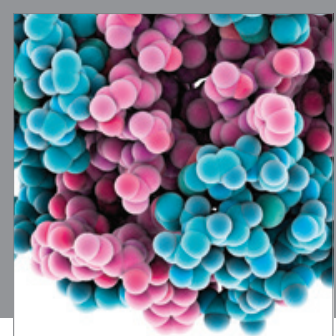

Journal of
Diabetes Research

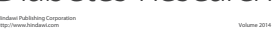

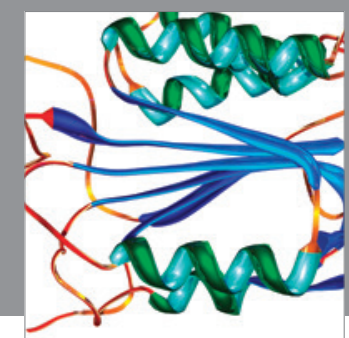

Disease Markers
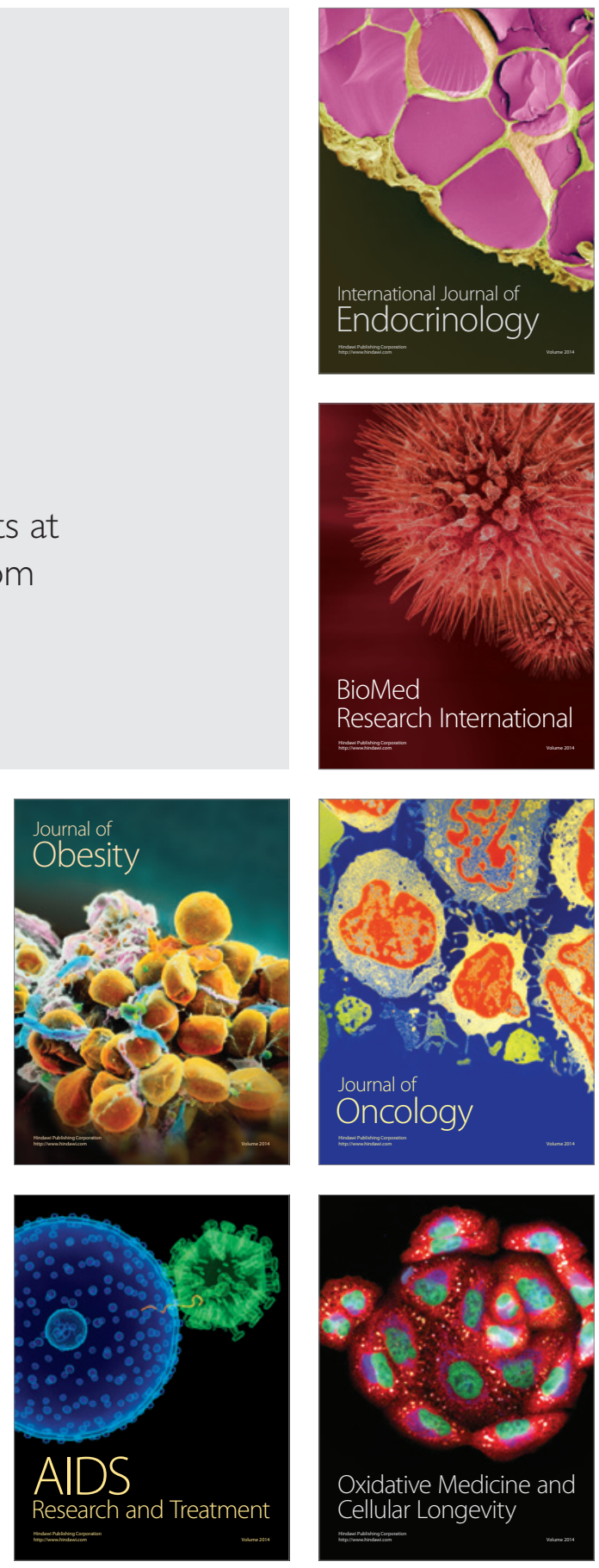